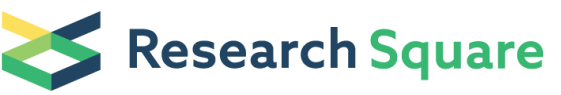 \\ Preprints are preliminary reports that have not undergone peer review. \\ They should not be considered conclusive, used to inform clinical practice, or referenced by the media as validated information.
}

\section{Management of LC Type I (LC-1) Pelvic Injuries with Complete Sacral Fracture : Is there a Role for Solitary Anterior Fixation?}

\section{Pengfei Wang}

Xi'an Honghui HospitalषXi'an Jiaotong University Health Science Center'

\section{Syed Ali}

Institute for Global Orthopaedic \& Traumatology,UCSF,USA

\section{Chen Fei}

Xi'an Honghui Hospital $\llbracket$ Xi'an Jiaotong University Health Science Center

\section{Binfei Zhang}

Xi'an Honghui Hospital区Xi'an Jiaotong University Health Science Center

\section{Xing Wei}

Xi'an Honghui Hospital ,Xi'an Jiaotong University Health Science Center

\section{Hu Wang}

Xi'an Honghui Hospital,Xi'an Jiaotong University Health Science Center

\section{Yuxuan Cong}

Xi'an Honghui Hospital,Xi'an Jiaotong University Health Science Center

\section{Hongli Deng}

Xi'an Honghui Hospital,Xi'an Jiaotong University Health Science Center

Yahui Fu

Xi'an Honghui Hospital,Xi'an Jiaotong University Health Science Center

\section{Yan Zhuang}

Xi'an Honghui Hospital,Xi'an Jiaotong University Health Science Center

Kun Zhang ( $\sim 13759994007 @ 163 . c o m$ )

Xi'an Honghui Hospital,Xi'an Jiaotong University

\section{Research Article}

Keywords: LC-1 pelvic fracture, complete sacral fracture, lateral compression, internal fixation, pelvic ring

Posted Date: August 10th, 2021

DOI: https://doi.org/10.21203/rs.3.rs-779203/v1 
License: (c) (i) This work is licensed under a Creative Commons Attribution 4.0 International License. Read Full License 


\section{Abstract}

Background: Management of LC-1 type pelvic injuries, particularly in patients with complete sacral fracture (LC-1 PICSF, OTA type 61-B2.1) remains controversial. Specific indications for solitary fixation remain unclear, and there is a paucity of outcomes data in comparison to combined fixation. We undertook a retrospective study in patients with LC-1 PICSFs to compare outcomes between solitary anterior fixation and combined anterior-posterior fixation.

Methods: A retrospective cohort study was conducted with enrollment from 2014 to 2015 at a single tertiary-referral center in China. Adults with operatively managed LC-1 PICSFs were enrolled. Patients with sacral displacement $<1 \mathrm{~cm}$ as assessed by axial CT received solitary anterior ring fixation (Group A); patients with displacement $\geq 1 \mathrm{~cm}$ received combined fixation of both the anterior and posterior rings (Group B). Reduction was confirmed by manipulation under anesthesia. Patients followed up for at least 24 months post-operatively. Primary outcome was function (Majeed score). Secondary outcomes included intraoperative characteristics, pain (VAS score), quality of fracture reduction (Tornetta and Matta radiographic grading), rate of non-union, early weight-bearing status, and complication rate.

Results: 68 (89\%) of 76 enrolled patients completed follow-up. Patients in Group A exhibited improved operative times, less time under fluoroscopy, and less blood loss as compared to Group B. There were no significant differences between Groups A and B regarding quality of fracture reduction, rate of union, functional outcomes, or rate of complications. Notably, Group B patients were more likely to achieve full early weight-bearing.

Conclusion: LC-1 PFCSFs can get benefits from ORIF; the treatment algorithm should be differently made following the degree of the sacral fractures displacement. Less than $1 \mathrm{~cm}$ sacral fracture displacement may get good functional outcomes from solitary anterior fixation. However, for the sacral fractures displacement greater or equal to $1 \mathrm{~cm}$, both the anterior and posterior pelvic ring should be surgical stabilization.

\section{Introduction}

Young and Burgess Lateral Compression Type I (LC-1) fractures account for up to $63 \%$ of all pelvic ring injuries, but optimal treatment remains controversial[1-6]. This fracture pattern is usually caused by a lateral impact force and is characterized by pubic ramus fractures and sacral compression fractures without vertical instability [2,3]. Although the incidence of LC-1 pelvic fractures is high, the optimal treatment algorithm remains under debate $[2,4-6]$. The assessment of stability in LC-1 pelvic ring fractures is an important factor in the treatment algorithm. Some authors[5-7] advocate a non-operative treatment based on the original work by Young and Burgess which views this fracture pattern as a stable injury because the main ligaments contributing to pelvic stability remain intact [2].Furthermore, they indicate that operatively treated patients had a significantly higher complication rate, especially in young 
men[8]. Others dispute the increased rate of complications in the surgically managed patient compared to those receiving non-operative treatment $[9,10]$.

Attempts have been made to qualify pelvic ring stability in LC-1 type fracture patterns by means of radiographic assessment[6]. Others advocate the notion of not relying merely on low sensitivity plain radiographs to evaluate stability. $[9,11,12]$. One of the reasons for this is because based on CT scans LC1 injuries represent a spectrum of injury severity, different fracture anatomy and potential instability[13]. Furthermore, assessment of pelvic ring stability through manipulation under anesthesia (MUA) revealed that almost $40 \%$ of LC-1 injuries were inherently unstable[14]. Based on these findings and the amount of displacement during the MUA, a modification of the Young and Burgess classification system for LC-1 injuries was proposed: 1) LC-1a (not requiring surgical treatment) and 2) LC-1b (may require surgical treatment)[14]. A recent prospective study utilizing intraoperative MUA to assess stability found that LC-1 injuries with a complete posterior sacral injury were all inheritably rotationally unstable and patients presenting with these fracture patterns would gain from surgical stabilization[15]. This has been confirmed by Bruce et al. that reported that LC- 1 fractures with complete sacral fractures and bilateral rami fractures displace at a significantly greater rate[16]. However, MUA is an examination is an assessment for which general anesthesia is needed and may not be the most cost-effective modality for predicting the stability or for deciding on course of management.

In case of a surgical intervention, most surgeons would likely fix the posterior pelvic ring fractures with a cannulated screw followed by the anterior pelvic ring fixation. Difficulties in reducing and fixating the posterior ring may arise in cases where the anterior ring is significantly displaced. The necessity of perfect posterior ring reduction and fixation is debatable since there is evidence that an anterior internal fixator can provide some indirect compression along the sacroiliac joint, which is beneficial and possibly sufficient for the stability of the pelvic ring[17]. To the best of our knowledge, there has been no study comparing the long-term functional outcomes and complications between surgically managed LC-1 pelvic fractures with different degrees of posterior ring displacement. The hypothesis is that the treatment algorithm of LC-1 PFCSFs should be separately made according to the degree of the sacral fractures displacement.

\section{Patients And Methods}

This retrospective comparative study was approved by our Institutional Review Board (No. 201404006). All patients who were admitted to our institution and fulfilled the following criteria were enrolled in the study. Inclusion criteria were (a) LC-1 pelvic fracture (OTA 61-B2.1) with a complete sacral fracture. This was defined as a visible fracture through the anterior and posterior cortices of the sacrum at the S1 level on the axial CT (computerized tomography) scan. (b) Patients older than 18 years, (c) no signs of a pathological fracture, (d) complete follow-up available. Patients with incomplete sacral fractures or those with an associated acetabular fracture were excluded. 
All the patients were evaluated pre-operatively using a standard radiological protocol including AP view, inlet view, outlet view and pelvic CT scan with three-dimensional reconstructions. The Young and Burgess classification systems was used to classify the fracture patterns. The axial CT scans at the S1/S2 level (according to the maximal displacement) were used for the measurement of fracture displacement of the posterior ring. A sacral fracture was deemed complete if a fracture line was visible through both the anterior and posterior cortices. The distance between either the anterior cortices or posterior cortices was measured at the $\mathrm{S} 1$ level.

Patients were allocated into one of two groups depending on the amount of displacement of the sacral fractures. Group 1 was comprised of patients with LC1 fractures with a displacement of less than $1 \mathrm{~cm}$. Group 2 was comprised by those that sustained LC- 1 fractures with a displacement greater or equal to $1 \mathrm{~cm}$.

The allocation and the treatment plan was made by two senior pelvic surgeons $\triangle \mathrm{Y} Z \mathrm{Z}$ and $\mathrm{K} Z \mathbb{Z}$ In case of controversy, a consensus is achieved by the majority of senior experienced surgeons in a morning review meeting. In Group 1, only the anterior pelvic fractures were reduced and fixed using plate, cannulated screws, infix, external fixator depending on the fracture patterns and local soft tissue condition. Patients in Group 2 underwent anterior pelvic fracture fixation in combination with sacral fractures fixation.

After successful induction of general anesthesia, the patient was placed supine on a radiolucent table. In Group 1, the anterior pelvic fracture was reduced and fixed through a Stoppa approach or ilioinguinal approach. In some cases, closed reduction and 6.5-mm diameter cannulated screw, or the infix[18] or exfix was inserted percutaneously. To avoid joint and intrapelvic penetration as well as for confirmation of screw positioning the procedure was performed under fluoroscopic control. Once the anterior ring fixation was completed the reduction and stability of pelvis were examined and confirmed under the anesthesia with the surveillance of the fluoroscopy[14]. In Group 2, the techniques for reduction and fixation of anterior pelvic fractures were identical to those used in Group 1 The posterior pelvic fractures were fixed by percutaneous sacroiliac joint screws. For dysmorphic sacral osseous pathways, techniques used were the tension band plate or pedicle screws connected to a transverse rod [19](Fig 1,2)

\section{Postoperative management}

Prophylactic use of antibiotics (Cefazolin, $1.0 \mathrm{~g}$, three times a day, LuKang pharmaceutical Co, China) was continued for 24-48 hours postoperatively. Intermittent compression devices and low molecular weight heparin (LMWH, 4100U, once a day, GlaxoSmithKline Co, UK) were used for venous thromboembolism (VTE) prophylaxis during hospital stay. After discharge patients used $10 \mathrm{mg}$ of rivaroxaban once a day until five weeks after the surgery. The postoperative rehabilitation protocol consisted of protected toe-touch weight-bearing for 6 weeks in Group 1 and immediate full weight-bearing activity in Group 2. Patients who are not able to safely ambulate were allowed to bed-to-chair transfers with assistance until they are advanced to partial weight-bearing activity at 4-6 weeks. 


\section{Data collection}

The patients were followed-up by an independent senior pelvic surgeon (Xing Wei) who were not involved in the surgery or the definitive care.

Baseline characteristics, operative data and post-operative data that were collected were: 1) Demographics: gender, age, mechanism of the accident, 2) Fracture type according to the Young and Burgess classification, injury pattern of the anterior and posterior pelvic ring, 3) Injury Severity Score (ISS), 4)Visual analog score (VAS, pre-and postoperative at 72 hours), 5) Surgery-related variables: time of operation, blood loss, fluoroscopy time, quality of the reduction according to the Tornetta and Matta radiographic grading [20], 6) Early weight-bearing status, 7) Functional outcome according to the most often used Majeed score grading [21, 22]. Finally, all complications were noted.

Follow-up evaluation included post-operative visits at 1, 2, 3, 6 months, one year and annually thereafter. The Majeed Score grading was used to assess the clinical and functional outcome in regard to pain (30 points), standing (36 points), sitting (10 points), sexual (4 points) function and walking (20 points). The total score was graded as excellent ( $\geq 85$ points), good (70-84 points), fair (55-69 points) or poor ( $<55$ points). The Tornetta and Matta radiographic grading assesses reduction and classifies displacement of less than $5 \mathrm{~mm}$ as excellent, $5-10 \mathrm{~mm}$ as good, $11-20 \mathrm{~mm}$ as fair, and $>20 \mathrm{~mm}$ as poor.

\section{Statistics}

IBM SPSS 19 statistical software (Chicago, IL, USA) was statistical analysis. Data were presented as means and standard deviations. Chi-square and Fisher exact tests were performed for the categorical variables as appropriate. Student t-test was used for comparison of continuous variables. A p-value of 0.05 was defined as statistically significant.

\section{Results}

Between June 2014 to December 2015, 180 pelvic ring fractures were treated at our level 1 trauma institution. Sixty-eight patients ( $37.8 \%)$ met all the inclusion criteria and were included in this study. There were 37 males and 31 females with a mean age of 39.4 years (range, 18-71) included. All patients were followed for an average of 29.3 \pm 5.9 months (range, 24-42 months). All fractures proceeded to union. The demographic data, trauma mechanism, additional injuries, ISS, anterior ring injury patterns are presented in Table 1. A significant difference in trauma mechanism between the two groups $(P<0.05)$, was identified but all other baseline characteristics were comparable.

Table 1

Demographic, injury data and surgical data of patients 


\begin{tabular}{|c|c|c|c|}
\hline & $\begin{array}{l}\text { Non-operative of posterior } \\
\text { pelvic } \\
\text { (group I, } n=36 \text { ) }\end{array}$ & $\begin{array}{l}\text { Operative of posterior pelvic (group } \\
\| I, n=32 \text { ) }\end{array}$ & $\begin{array}{l}P \\
\text { level }\end{array}$ \\
\hline $\begin{array}{l}\text { Age (mean } \pm S D \text {, } \\
\text { years) }\end{array}$ & $38.1 \pm 13.5$ & $40.8 \pm 15.5$ & 0.447 \\
\hline Sex (male冈female) & & & 0.330 \\
\hline M & 19 & 21 & \\
\hline $\mathrm{F}$ & 17 & 11 & \\
\hline $\begin{array}{l}\text { Mechanism of } \\
\text { accident } \ n \% \square\end{array}$ & & & 0.033 \\
\hline Crush by heavy & $6 \rrbracket 16.7 \% \rrbracket$ & $2 \bowtie 6.3 \% \rrbracket$ & \\
\hline MVA & 13(36.1\%) & $20 \otimes 62.5 \% \rrbracket$ & \\
\hline Fall from height $\geq 3 \mathrm{~m}$ & $8(22.2 \%)$ & $1 \rrbracket 3.1 \% \rrbracket$ & \\
\hline Fall from height $<3 \mathrm{~m}$ & $9(25 \%)$ & $9 \llbracket 28.1 \% \rrbracket$ & \\
\hline ISS & & & 0.520 \\
\hline$\bigotimes 16$ & 23 & 18 & \\
\hline$\geq 16$ & 13 & 14 & \\
\hline $\begin{array}{l}\text { Anterior ring injury } \\
\text { pattern }\end{array}$ & & & 0.345 \\
\hline Ipsilateral & $18(50 \%)$ & $20(62.5 \%)$ & \\
\hline Contralateral & $7(19.4 \%)$ & $7(21.9 \%)$ & \\
\hline Bilateral & $11(30.6 \%)$ & $5(15.6 \%)$ & \\
\hline Associated injury & & & 0.796 \\
\hline None & 20 & 13 & \\
\hline Head & 2 & 3 & \\
\hline Thorax & 3 & 4 & \\
\hline Abdomen & 3 & 3 & \\
\hline Upper extremity & 4 & 2 & \\
\hline Lower extremity & 3 & 5 & \\
\hline Multi-injury & 1 & 2 & \\
\hline
\end{tabular}


After anterior fixation of the pelvic ring fractures in group 1 all were deemed stable after MUA. At the final follow-up, reduction of the sacral fractures according to the Tornetta and Matta radiographic grading was excellent and good for Group 1 (91.7\%) and Group 2 (87.6\%) respectively. The functional outcome score according to Majeed scores grading was excellent in both groups. (88.9\% and $87.5 \%$ in Group 1 and Group 2 respectively.) . There were no statistically significant differences in the Tornetta and Matta radiographic grading, Majeed grading scores between Group 1 and Group 2(p>0.05). The mean operation time, the mean blood loss and the mean radiological time in Group 1 were significantly less than in Group 2 respectively. (117.6 \pm 46.0 vs. $158.9 \pm 28.1 \mathrm{~min}, 187.5 \pm 133.0$ vs. $264.1 \pm 158.2 \mathrm{ml}$, and $12.58 \pm 3.7$ vs. $74.28 \pm 18.8$ second, $\mathrm{p} \otimes 0.05)$. There was a significant difference in weight-bearing status between these two groups $(\mathrm{p} \otimes 0.05)$ (table 2$)$.

\section{Table 2}

The comparison of surgical factors, radiological outcomes, and functional outcomes, between group 1 and group 2 


\begin{tabular}{|c|c|c|c|}
\hline & $\begin{array}{l}\text { Non-operative of } \\
\text { posterior pelvic } \\
\text { (group } 1, n=36 \text { ) }\end{array}$ & $\begin{array}{l}\text { Operative of posterior pelvic } \\
\text { (group } 2, n=32 \text { ) }\end{array}$ & P level \\
\hline Fixation of anterior -ring & & & 0.14 \\
\hline plate & 24 & 22 & \\
\hline cannulated screw & 6 & 9 & \\
\hline Infix & 5 & 0 & \\
\hline Ex-fix & 1 & 1 & \\
\hline Fixation of posterior -ring & & & - \\
\hline Plate & NA & $9 \llbracket 28.1 \% \rrbracket$ & \\
\hline cannulated screw & NA & $16(50 \%)$ & \\
\hline Rod with pedicle screws & NA & $7(21.9 \%)$ & \\
\hline $\begin{array}{l}\text { Operation time } \\
\text { (min, from incision to } \\
\text { closure) }\end{array}$ & $117.6 \pm 46.0$ & $158.9 \pm 28.1$ & 0.000 \\
\hline Blood loss(ml) & $187.5 \pm 133.0$ & $264.1 \pm 158.2$ & 0.034 \\
\hline Fluoroscopy time $₫$ seconds $\rrbracket$ & $12.58 \pm 3.7$ & $74.28 \pm 18.8$ & 0.000 \\
\hline Pain & $6.47 \pm 1.61^{\star}$ & $7.47 \pm 1.54 \#$ & $0.000 *$ \\
\hline Pre-operation & & & $0.000 \#$ \\
\hline Post-operation & $3.05 \pm 0.98^{*}$ & $4.06 \pm 1.32 \#$ & \\
\hline Early weight-bearing status & & & 0.000 \\
\hline Non-weightbearing & 9 & 7 & \\
\hline Partial weight-bearing & 27 & 3 & \\
\hline Full weight-bearing & 0 & 22 & \\
\hline \multicolumn{4}{|l|}{ Radiographic grades } \\
\hline $\begin{array}{l}\text { (Tornetta and Matta } \\
\text { radiographic grading) }\end{array}$ & & & 0.948 \\
\hline Excellent & $29(80.6 \%)$ & $25(78.2 \%)$ & \\
\hline Good & $4(11.1 \%)$ & $3(9.4 \%)$ & \\
\hline Fair & $3(5.5 \%)$ & $3(6.2 \%)$ & \\
\hline
\end{tabular}




\begin{tabular}{|lcc|}
\hline Poor & $0 \otimes 0 \% 区$ & $1(3.1 \%)$ \\
\hline $\begin{array}{l}\text { Function outcomes } \\
\text { (Majeed scores grading) }\end{array}$ & & 0.693 \\
\hline Excellent & $23(63.9 \%)$ & $16(50.0 \%)$ \\
\hline Good & $9(25 \%)$ & $12(37.5 \%)$ \\
\hline Fair & $3(8.3 \%)$ & $3(9.3 \%)$ \\
\hline Poor & $1(2.8 \%)$ & $1(3.1 \%)$ \\
\hline $\begin{array}{l}\text { Tips: }{ }^{*} \text { compare the pre-operation with the post-operation in group 1. \# compare the pre-operation with } \\
\text { the post-operation in group 2. NA: none available }\end{array}$ \\
\hline
\end{tabular}

Fourteen patients developed venous thromboembolism (VTE). 13 patients were diagnosed with deep vein thrombosis (DVT) including 6 DVT in Group1, 7 DVT and 1 non-fatal pulmonary embolism (PE) in Group 2. There were no deep infections noted. Four patients were diagnosed with $L 5$ nerve root neurological deficits. In Group 1, one patient preoperatively presented paresthesia located in the dorsal of the foot. The other 3 patients were in Group 2. Two of these three patients present preoperatively, the other one was injured during the surgery. all the patients with L5 nerve root neurological deficits completely recovered except for the patient who had the iatrogenic L5 injury in Group 2. The patient suffered from residual weakness of the extensor hallucis longus. Surgical exploration and decompression were offered, but the patient refused. Three patients had implant-related complications. Two patients were in Group 1 and one patient was in Group 2 respectively. These three patients included one patient with a pubic rim delayed union and loosening of screws in the anterior plate without symptoms. One patient experienced injury to the lateral femoral cutaneous nerve (LFCN) presenting as paresthesia. The symptom of LFCN recovered fully after implant removed at six months. The other patient experienced hardware irritation caused by a pedicle screw. After removal of hardware at three months the symptoms dissipated. No heterotopic ossifications or traumatic sacroiliac arthritis were observed. There was no significant difference in complication rates between these two group $(p>0.05)$ (Table 3 ).

Table 3

The comparison of complications between group 1 and group 2 


\begin{tabular}{|c|c|c|c|}
\hline Complications & $\begin{array}{l}\text { Non-operative of posterior pelvic } \\
\text { (group } 1, n=36\end{array}$ & $\begin{array}{l}\text { Operative of posterior pelvic } \\
\text { (group } 2, n=32 \text { ) }\end{array}$ & $\begin{array}{l}P \\
\text { level }\end{array}$ \\
\hline & & & 0.688 \\
\hline $\begin{array}{l}\text { nerve root } \\
\text { injury }\end{array}$ & 1 (pre-operative) & $\begin{array}{l}3 \bowtie 2 \text { patients pre-operative, } 1 \\
\text { patient post- operative } \rrbracket\end{array}$ & \\
\hline VTE & 6 (DVT) & 8 (7 DVT, 1 non-fatal PE) & \\
\hline \multirow{2}{*}{$\begin{array}{l}\text { Implant- } \\
\text { related }\end{array}$} & 1 LFCN injury $『$ recovered $\rrbracket$ & 1 implant irritation & \\
\hline & $\begin{array}{l}1 \text { asymptomatic screw loosening and } \\
\text { delayed union of the pubic rim }\end{array}$ & & \\
\hline
\end{tabular}

\section{Discussion}

The current study found that LC-1 PFCSFs could get benefits from the open reduction and internal fixation. The treatment algorithm should be separately made according to the degree of the sacral fractures displacement.

Stable LC-1 fractures can get good outcomes from conservative treatment because they will not displace under normal physiological weight bearing. Conversely, unstable patterns or displaced fractures are usually treated with surgical reduction and stabilization[23-25]

Determining whether or not an LC-1 fracture is stable remains challenging. [10] Magnetic resonance imaging and ultrasonography have been proposed as adjuncts, but their clinical utility has not yet been elucidated $[26,27]$. Recently, the predicted value of pelvic ring instability by positive MUA was verified by several studies[14, 15]. By intraoperative MUA, Tosounidis et al. [15] demonstrated that the LC-1 injuries with a complete posterior sacral injury are inheritably rotationally unstable. Sagi et al[14] reported that nearly $40 \%$ of LC- 1 pelvic fracture was operatively treated with/without posterior ring fixation. Whereas, no more details of the long-term functional results were recorded. On the other hand, Whiting et al. reported that immediate weight-bearing as tolerated seems safe in patients with pelvic ring injuries who have had a negative MUA[7]. Although the MUA may be the most reliable, it requires general anesthesia and may not be cost-effective, studies to evaluate this is warranted. Evaluation of pelvic ring stability in LC-1 type fractures, the X-ray or CT scan is widely used. According to Bruce et al. using CT scans, complete sacral fracture and bilateral rami fractures displace more prone to future displacement [16]. 
Previous clinical and biomechanical study $[17,28,29]$ found that in partially unstable LC- 1 fractures, fixation of the anterior pelvic ring only, which was similar to Group 1 in the current study, can provide some indirect compression along the sacroiliac joints, which can be beneficial for the functional outcomes. We compare the outcomes between the solitary anterior fixation and anterior-posterior pelvic ring fixation. Kanakaris [29] carried out a comparative study between the displacement of anterior or posterior pelvic fractures less $5 \mathrm{~mm}$ and more than $2 \mathrm{~cm}$ assessment during the EUA. However, the spectrum was broad, they did not mention the intermediate displacement of pelvic fractures. Although, Gaski et al. [5] investigated the intermediate displacement which was limited to the initial displacement less than $1 \mathrm{~cm}$ by the measurement in the plain radiographs, however, the measurement has the inherently inaccurate defect, which has been confirmed by the previous study. Lin et al. reported that $45.5 \%$ of patients with bilateral ramus fractures and $42.0 \%$ of patients with dual-ramus fractures had concomitant sacral fractures not observed on plain radiographs yet [11] let alone the accurate measurement. This issue can be solved by the CT scan. In the current study, we used $1 \mathrm{~cm}$ measured in the CT scan as the threshold to divide the displacement was much more reasonable.

Surgical intervention in these two groups was associated with significantly reduced pain post-operatively (3.05 \pm 0.98 in Group 1 and 4.06 \pm 1.32 in Group 2). The results were similar to the previous reports[15, 19]. These results support the view that surgical intervention provides significant pain relief and allow early ambulation. Simultaneously, in solitary anterior fixation (Group 1), the operation time was reduced significantly $(117.6 \pm 46.0$ vs. $158.9 \pm 28.1 \mathrm{mins})$, the saved time was similar to the previous reports[30, 31]. With the shortening of the operation time, the surgeons and patients also have less radiation exposure, which was essential for both patient's and surgeon's health. The current study showed that the excellent and good rate of functional outcomes (Majeed scores) was $88.9 \%$ and $87.5 \%$ in Group 1 and Group 2 respectively. There was no significant difference between Group 1 and Group 2 ( $p>0.05$ ). These functional outcomes certified that patients with unstable LC-1 pelvic fracture would get benefits from surgical stabilization[15]. The functional outcomes seemed better than the non-operation, which was performed by Gaski et al. in the complete sacral fracture with displacement less than $1 \mathrm{~cm}[5]$.

The current study found that, in Group 1, after the anatomic reduction and internal fixation of the anterior ring, the displacement of the posterior ring was also reduced, there was no significant difference in the radiographic radiologic outcomes between this two groups $₫ p>0.05$ ). Meanwhile, there was also no significant difference between the fixation pattern of the anterior ring $(p>0.05)$. The biomechanical study indicated that the retrograde screw could provide the comparable stability to reconstruction plate[32], meanwhile, the latest comparative study showed that the modified pedicle screw-rod fixation (infix) and anterior external fixation could provide similar satisfactory clinical outcomes for anterior pelvic ring fracture [33]. Therefore, the selection of the implant for anterior ring fixation did not affect the outcomes in LC-1 pelvic fractures. The final follow-up of this group (Group 1) showed that all sacral fractures healed. We deduced that after the anatomic reduction of the anterior ring, the posterior ring restored to the correct position, the tension of the posterior ligament complex was reduced, which was beneficial to the healing of the posterior ring injury. Usually, the bilateral pubic ramus fractures were greater unstable than the unilateral pubic ramus fracture; however, there were no significant differences in functional outcomes 
after the ORIF(open reduction and internal fixation) of the anterior pelvic ring $(p>0.05)$. We believe that, with the anterior ring fixed, the stability of the whole pelvic ring was significantly increased. The results have been approved by the finite element analysis[34].

The current study also found that after stable fixation, in the early stage, there was a significant difference of early weight-bearing between these two groups $(p<0.05)$. It seemed to be that the patients were more aggressive in weight-bearing in Group 2, which might be attributed to pain relief.

The current study also found that the complications were no significant difference between Group 1 and Group2 ( $P>0.05)$. The most frequent complication was VTE, $20.6 \%$ of the patients developed VTE $(14 / 68$, six silent DVT in group 1, six silent DVT and one non-fatal PE in group 2), which may be attributed to the regularly VTE screening pre-operatively and post-operatively in our hospital. Although the thrombosis prophylaxis was routinely prescribed to the patients. Kim reported a similar incidence of DVT (20\%)[35]. However, in Kim's study, the rate of clinically significant VTE was much higher than the current study. In Group 1, one patient got INFIX-related LFCN injury, which gradually recovered after the removal of the implant 3 months later. In group 2, one patient got postoperative L5 nerve root injury, with some residual weakness of extensor hallucis longus, which may due to the iatrogenic injury. Surgical exploration and decompression were offered, but the patient refused; The preoperative L5 injury gradually recovered in both groups. In group 2, one patient got pedicle screw related skin irritation; the irritative symptoms recovered gradually after implant removed.

\section{Limitations}

There are some limitations to the current study. First, as a retrospective control study, the patients were not randomly divided into two groups. Second, the current study did not compare the outcomes with the incomplete displacement of the sacral fracture of LC-1 pelvic fractures, which may potentially expand the surgical indication. Third, due to the inherent low incidence and small sample size, the study was not stratified according to the displacement of sacral fracture. Fourth, although the final functional outcomes seem good through solitary anterior fixation, this fixation need to be verified by the biomechanical study.

\section{Conclusion}

LC-1 PFCSFs can get benefits from ORIF; the treatment algorithm should be differently made following the degree of the sacral fractures displacement. Less than $1 \mathrm{~cm}$ sacral fracture displacement may get good functional outcomes from solitary anterior fixation. However, for the sacral fractures displacement greater or equal to $1 \mathrm{~cm}$, both the anterior and posterior pelvic ring should be surgical stabilization.

\section{Abbreviations}

PICSF: Pelvic Injuries with Complete Sacral Fracture; ORIF: open reduction and internal fixation; CT: computerized tomography; MUA: manipulation under anesthesia;LMWH: low molecular weight 
heparin;VTE: venous thromboembolism; DVT : deep vein thrombosis; PE: pulmonary embolism; LFCN: lateral femoral cutaneous nerve; Iss: injury severity score; VAS: visual analog score;

\section{Declarations}

\section{Acknowledgements}

None

\section{Authors' contributions}

Pengfei Wang and Syed Ali carried out the study and writing of the manuscript. Chen Fei and Binfei Zhang confirmed the completeness and validity of the data. Syed Ali was a major contributor in revising it critically. Kun Zhang and Yan Zhuang carried out the study design. Xing Wei, Hu Wang, Yuxuan Cong, Hongli Deng and Yahui Fu contributions in data collecting and drafting. All authors read and approved the final manuscript.

\section{Funding}

Not applicable.

\section{Availability of data and materials}

This article only includes summarized data from this study. Datasets are available from the corresponding author on reasonable request.

\section{Ethics approval and consent to participate:}

This study was approved by the Ethics Committee and Institutional Review Board of Xi'an Honghui Hospital, Xi'an Jiaotong University Health Science Center.

\section{Consent for publication}

All patients involved in this study gave their consent for the anonymized data to be used for scientific purposes and published in a scientific journal. The signed consent forms are stored at the database of the Xi'an Honghui Hospital.

\section{Competing interests}


The authors declare that they have no competing interests.

\section{References}

1. Manson T, O'Toole RV, Whitney A, Duggan B, Sciadini M, Nascone J. Young-Burgess classification of pelvic ring fractures: does it predict mortality, transfusion requirements, and non-orthopaedic injuries? J Orthop Trauma. 2010;24:603-9. DOI 10.1097/BOT.0b013e3181d3cb6b.

2. Young JW, Burgess AR, Brumback RJ, Poka A. Pelvic fractures: value of plain radiography in early assessment and management. Radiology. 1986;160:445-51. DOI 10.1148/radiology.160.2.3726125.

3. Osterhoff G, Scheyerer MJ, Fritz Y, Bouaicha S, Wanner GA, Simmen HP, Werner CM. Comparing the predictive value of the pelvic ring injury classification systems by Tile and by Young and Burgess. Injury. 2014;45:742-7. DOI 10.1016/j.injury.2013.12.003.

4. Hoffmann MF, Jones CB, Sietsema DL. Persistent impairment after surgically treated lateral compression pelvic injury. Clin Orthop Relat Res. 2012;470:2161-72. DOI 10.1007/s11999-012-22471.

5. Gaski GE, Manson TT, Castillo RC, Slobogean GP, O'Toole RV. Nonoperative treatment of intermediate severity lateral compression type 1 pelvic ring injuries with minimally displaced complete sacral fracture. J Orthop Trauma. 2014;28:674-80. DOI 10.1097/BOT.0000000000000130.

6. Sembler Soles GL, Lien J, Tornetta P 3rd. Nonoperative immediate weightbearing of minimally displaced lateral compression sacral fractures does not result in displacement. J Orthop Trauma. 2012;26:563-7. DOI 10.1097/BOT.0b013e318251217b.

7. Whiting PS, Auston D, Avilucea FR, Ross D, Archdeacon M, Sciadini M, Collinge CA, Sagi HC, Mir HR. Negative Stress Examination Under Anesthesia Reliably Predicts Pelvic Ring Union Without Displacement. J Orthop Trauma. 2017;31:189-93. DOI 10.1097/BOT.0000000000000766.

8. Hoch A, Schneider I, Todd J, Josten C, Bohme J. (2016) Lateral compression type B 2 - 1 pelvic ring fractures in young patients do not require surgery. European journal of trauma and emergency surgery: official publication of the European Trauma Society. DOI 10.1007/s00068-016-0676-3.

9. Hagen J, Castillo R, Dubina A, Gaski G, Manson TT, O'Toole RV. Does Surgical Stabilization of Lateral Compression-type Pelvic Ring Fractures Decrease Patients' Pain, Reduce Narcotic Use, and Improve Mobilization? Clin Orthop Relat Res. 2016;474:1422-9. DOI 10.1007/s11999-015-4525-1.

10. Beckmann JT, Presson AP, Curtis SH, Haller JM, Stuart AR, Higgins TF, Kubiak EN. Operative agreement on lateral compression-1 pelvis fractures. a survey of 111 OTA members. J Orthop Trauma. 2014;28:681-5. DOI 10.1097/BOT.0000000000000133.

11. Lin EA, Min W, Christoforou D, Tejwani NC. Young and burgess type I lateral compression pelvis fractures: a comparison of anterior and posterior pelvic ring injuries. Orthopedics. 2010;33:389. DOI 10.3928/01477447-20100429-05.

12. Schicho A, Schmidt SA, Seeber K, Olivier A, Richter PH, Gebhard F. Pelvic X-ray misses out on detecting sacral fractures in the elderly - Importance of CT imaging in blunt pelvic trauma. Injury. 
2016;47:707-10. DOI 10.1016/j.injury.2016.01.027.

13. Lefaivre KA, Padalecki JR, Starr AJ. What constitutes a Young and Burgess lateral compression-I (OTA 61-B2) pelvic ring disruption? A description of computed tomography-based fracture anatomy and associated injuries. J Orthop Trauma. 2009;23:16-21. DOI 10.1097/BOT.0b013e31818f8a81.

14. Sagi HC, Coniglione FM, Stanford JH. Examination under anesthetic for occult pelvic ring instability. J Orthop Trauma. 2011;25:529-36. DOI 10.1097/BOT.0b013e31822b02ae.

15. Tosounidis T, Kanakaris N, Nikolaou V, Tan B, Giannoudis PV. Assessment of Lateral Compression type 1 pelvic ring injuries by intraoperative manipulation: which fracture pattern is unstable? International orthopaedics. 2012;36:2553-8. DOI 10.1007/s00264-012-1685-4.

16. Bruce B, Reilly M, Sims S. OTA highlight paper predicting future displacement of nonoperatively managed lateral compression sacral fractures: can it be done? J Orthop Trauma. 2011;25:523-7. DOI 10.1097/BOT.0b013e3181f8be33.

17. Vigdorchik JM, Esquivel AO, Jin X, Yang KH, Vaidya R. Anterior internal fixator versus a femoral distractor and external fixation for sacroiliac joint compression and single stance gait testing: a mechanical study in synthetic bone. International orthopaedics. 2013;37:1341-6. DOI 10.1007/s00264-013-1890-9.

18. Chaus GW, Weaver MJ. Anterior Subcutaneous Internal Fixation of the Pelvis: Placement of the INFIX. Operative Techniques in Orthopaedics. 2015;25:262-9. DOI https://doi.org/10.1053/j.oto.2015.08.006.

19. Wang H, Fu YH, Ke C, Zhuang Y, Zhang K, Wei X, Li Z, Lei JL, Zhang BF, Liu P. Minimally invasive stabilisation of posterior pelvic ring instabilities with pedicle screws connected to a transverse rod. International orthopaedics. 2018;42:681-6. DOI 10.1007/s00264-017-3714-9.

20. Tornetta P 3rd, Matta JM. (1996) Outcome of operatively treated unstable posterior pelvic ring disruptions. Clinical orthopaedics and related research:186-193.

21. Lefaivre KA, Slobogean GP, Valeriote J, O'Brien PJ, Macadam SA. Reporting and interpretation of the functional outcomes after the surgical treatment of disruptions of the pelvic ring: a systematic review. The Journal of bone joint surgery British volume. 2012;94:549-55. DOI 10.1302/0301620X.94B4.27960.

22. Majeed SA. Grading the outcome of pelvic fractures. The Journal of bone joint surgery British volume. 1989;71:304-6.

23. Gordon RO, Mears DC. Lateral compression injury of the pelvis. A case report. The Journal of bone joint surgery American volume. 1991;73:1399-401.

24. Bellabarba C, Ricci WM, Bolhofner BR. Distraction external fixation in lateral compression pelvic fractures. J Orthop Trauma. 2006;20:7-14.

25. Lindahl J, Hirvensalo E, Bostman O, Santavirta S. Failure of reduction with an external fixator in the management of injuries of the pelvic ring. Long-term evaluation of 110 patients. The Journal of bone joint surgery British volume. 1999;81:955-62. 
26. Gary JL, Mulligan M, Banagan K, Sciadini MF, Nascone JW, O'Toole RV. Magnetic resonance imaging for the evaluation of ligamentous injury in the pelvis: a prospective case-controlled study. J Orthop Trauma. 2014;28:41-7. DOI 10.1097/BOT.0b013e318299ce1b.

27. Zhang BF, Zhang $H$, Wang PF, Wang $H$, Lei JL, Fu YH, Cong $Y X$, Huang H, Huo XM, Zhuang $Y$, Zhang $\mathrm{K}$. The role of ultrasonography in examination of the stability of Tile-B2 pelvic fractures: 7 case reports and a literature review. Medicine. 2017;96:e8100. DOI 10.1097/MD.0000000000008100.

28. Van den Bosch EW, Van der Kleyn R, Hogervorst M, Van Vugt AB. Functional outcome of internal fixation for pelvic ring fractures. The Journal of trauma. 1999;47:365-71.

29. Kanakaris NK, Tzioupis C, Nikolaou VS, Giannoudis PV. Lateral compression type I injuries of the pelvic ring: Are they mechanically stable? Injury Extra. 2009;40:1129-30.

30. Shetty AP, Bosco A, Perumal R, Dheenadhayalan J, Rajasekaran S. Midterm radiologic and functional outcomes of minimally-invasive fixation of unstable pelvic fractures using anterior internal fixator(INFIX) and percutaneous iliosacral screws. Journal of clinical orthopaedics trauma. 2017;8:241-8. DOI 10.1016/j.jcot.2017.05.009.

31. Nork SE, Jones CB, Harding SP, Mirza SK, Routt ML Jr. Percutaneous stabilization of U-shaped sacral fractures using iliosacral screws: technique and early results. J Orthop Trauma. 2001;15:238-46.

32. Simonian PT, Routt ML Jr, Harrington RM, Tencer AF. Internal fixation of the unstable anterior pelvic ring: a biomechanical comparison of standard plating techniques and the retrograde medullary superior pubic ramus screw. J Orthop Trauma. 1994;8:476-82.

33. Bi C, Wang Q, Wu J, Zhou F, Zhang F, Liang H, Lyu F, Wang J. Modified pedicle screw-rod fixation versus anterior pelvic external fixation for the management of anterior pelvic ring fractures: a comparative study. J Orthop Surg Res. 2017;12:185. DOI 10.1186/s13018-017-0688-7.

34. Lei J, Zhang Y, Wu G, Wang Z, Cai X. (2015) The Influence of Pelvic Ramus Fracture on the Stability of Fixed Pelvic Complex Fracture. Computational and mathematical methods in medicine 2015:790575. DOI 10.1155/2015/790575.

35. Kim JW, Oh CW, Oh JK, Baek SG, Lee BJ, Hong HP, Min WK. The incidence and the risk factors of venous thromboembolism in Korean patients with pelvic or acetabular fractures. Journal of orthopaedic science: official journal of the Japanese Orthopaedic Association. 2014;19:471-7. DOI 10.1007/s00776-014-0553-z.

\section{Figures}



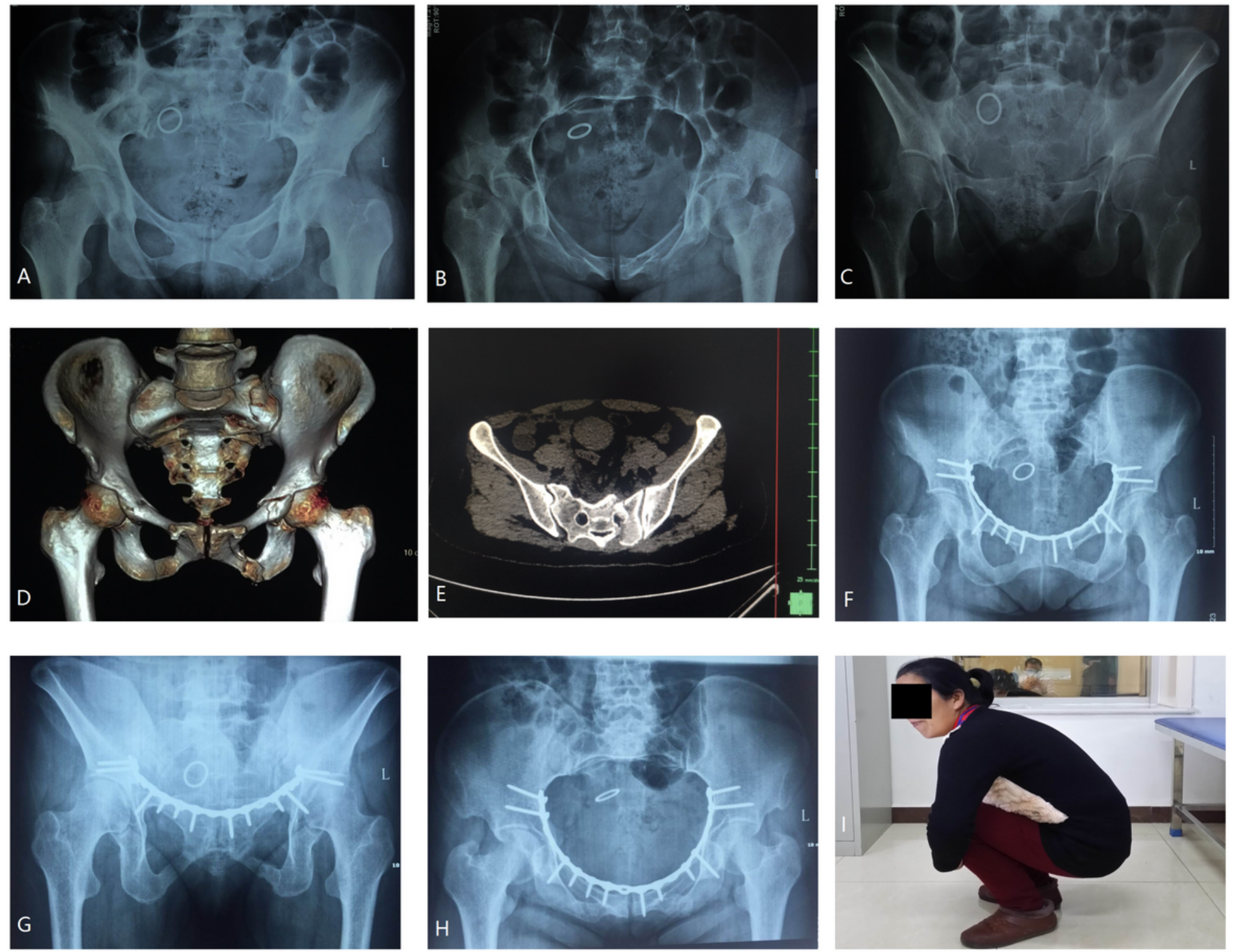

\section{Figure 1}

A 43-year-old female presenting with pelvic ring fractures (Young \& Burgess LC-1/Tile B2). Preoperative $A P$ view $(A)$, inlet view $(B)$, outlet view $(C)$ showed both pubic rami and a transforaminal sacral fracture on the left side. The CT scan(D) and 3D-reconstruction (E)showed the sagittal fracture line across the anterior and posterior cortex of S2 with minimal displacement. The pubic rami fractures were fixed through modified Stoppa approach. At final follow-up, the radiographs $\mathbb{F G H} \mathrm{F}$ and functional photographs (I) showed that the fractures healed, and the function recovered well. 

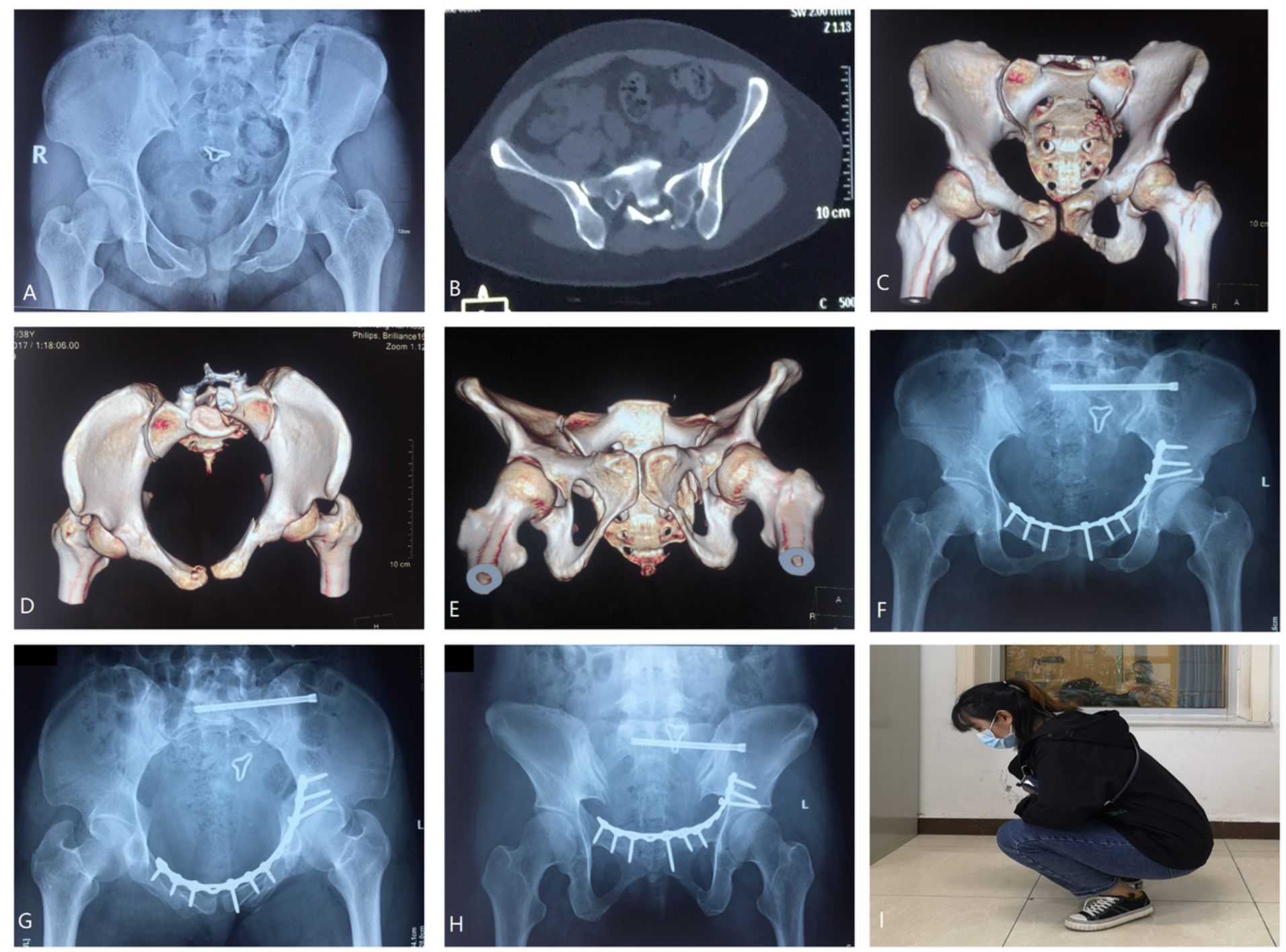

Figure 2

Radiographs of 32-year-old female with pelvic ring fractures (Young \& Burgess LC-1/Tile B2).Preoperative

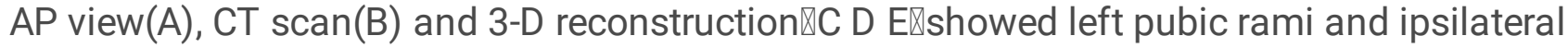
transforaminal sacral fracture with significant displacement. The pubic rami fracture was reduced and fixed through modified Stoppa approach followed by a sacroiliac screw inserted percutaneously. Postoperative radiographs $(\mathrm{F} \mathrm{G} \mathrm{H})$ showed the reduction and fixation was well. The final follow-up photograph showed the function recovered well. 